\title{
Serious Games for the Development of Learning
}

\author{
Loubna El Azizi, Aziz Arbai \\ Department of mathematics. Laboratory: Algebra and Operator Theory, Faculty of Sciences \\ UniversityAbdelmalek Essaadi \\ Tetouan, Morocco \\ loubna.elazizi@outlook.com,arbai_aziz@yahoo.com
}

\begin{abstract}
With the advent of interactive media, learning by playing is taking a variety of forms. Serious game, this term may seem contradictory, in reality it reflexes a very current reality, it rests on the video culture playful learners. This type of games is appropriate for investing in classrooms, the idea is to make learning more interactive and motivating. They have been developed to enable learners to build their own knowledge, skills and know-how to develop high-level skills to deal with complex situations.

In this paper, we present the concept of serious game, and our educational software who contain the attractive exercises and a serious game for mathematics. We design this softwarein Arabic to make mental calculation appreciate to novicestudents. And we believe that this type of software can be used to increasestudents'motivation to learn, and their interest in mental calculation.
\end{abstract}

Keywords-component; Serious Games; Education; Game; Learning; Video game

\section{Introduction}

The various works of psychologists have shown that man uses play in a natural way, in all areas of his life, as a pedagogical means to contribute to his emotional, sensory, motor, cognitive, intellectual and social development. So the introduction of the game in an educational context is not a new idea. But what is new is the relationship between learning and the numerical practices of learners.

In the 2000s, the concept of Serious Game is required to propose new applications based on the playful video culture of the learners.

In his research, Marc Prensky, explained that young people prefer images to texts, multitasking processes, networking and especially: "They prefer games to" serious "work. (Prensky, 2001), think and act differently from previous generations. Therefore, he recommends that pedagogies based onvideo games that can motivate learners and evoke serious games (Prensky, 2003).

In 2003, James Paul Gee takes up these arguments and develops them and demonstrates that video games make learning more effective and enjoyable. They encourage active, contextualized learning. They promote learners' commitment, their intuitiveness.

Over the past few years, serious games have been used in many sectors such as education, health, defense, industry, civil security and science. And they take an increasingly important place in the educational 
sphere. Our goal is to design an educational software in Arabic that contains interactive exercises in mathematics and a serious game designed to make mental calculation appreciate to novice and apprentices' students, after that we will integrate this game in a pedagogical scenario and we will Determine the impact of integrating this type of game on the learning development of learners.

In this article, we present the concept of serious games, determining their definition, their history, their categories, and their characteristics, and then we determine the impacts of integrating this type of game in class and the problems posed a priori by its elaboration, after we address the problematic which led us to develop this new type of digital resource "Serious Game" for the learning of mathematics, and especially the mental calculation. In the end, we conclude by a conclusion as well as our future work.

\section{Why the Serious Games?}

The emerging use of serious games poses a number of questions, the first of which relates to the definition of the expression "Serious Game", it history, it categories, and it purposes.

\subsection{What is a Serious Game?}

Definition:

Several definitions of serious game have been proposed by various organizations and authors:

Definition of Zyda (2005): American researcher who participated in the development of "America's Army", specifies that the Serious Game is:

"A cerebral challenge, played with a computer according to specific rules, which uses entertainment as an added value for training and training in institutional or private environments in the fields of education, health, Civil security, as well as for communication strategy purposes. "

Definition of Julian ALVAREZ (2007): French Researcher

"Computer application, the aim of which is to combine at the same time serious aspects (Serious) such as, but not limited to, teaching, learning, communication, or information, with ludic springs coming from the Video game (Game). Such an association, which takes place through the implementation of a "pedagogical scenario", is therefore aimed at moving away from mere entertainment.

Definition of CERIMES: Center for resources and information on multimedia for higher education.

"A real training tool, communication, simulation, [the serious game is] a sort of useful declination of the video game at the service of the professionals. "Serious Games are applications developed from advanced video game technologies, using the same design and know-how approaches as the classic game (3D realtime, simulation of objects, Individuals, environments ...) but which go beyond the sole dimension of entertainment."

From this different definition, we can conclude that the Serious game is a game that combines a serious intention with playful springs of video games. So we take a video game and we associate a utility function with it. The Serious Game must have three utility functions: Dispense a message, provide training and allow data collection.

Serious Games = Serious dimension + Videoludic dimension 


\subsection{History of Serious Game :}

The history of the Serious Games goes back a decade. The Renaissance humanists used the oxymoron "Serio Ludere". This term refers to the idea of dealing with a serious topic with an amusing approach. So, the first traces of studies on learning through play have been in Italy among humanists.

"Called" Serio Ludere ", this approach, which could be translated as" play seriously ", would refer in particular to the notion of using humor to pass serious notions. " Julian Alvarez (2007).

As early as 1960, Business Games were introduced in universities, schools and businesses, in particular to encourage the learning of managerial techniques. The teaching technique consists of using role-playing games or modified sets of trays to train learners to react well in typical situations. It was also during this period that the term Ludo Educative (Edutainment) appeared to designate the playful activities that could be used to channel children's attention in air-conditioned centers, museums and nursery schools.

In 1970, the expression Serious Game was first used in the United States by the American researcher Clark Abt in his book entitled Serious Game. This researcher sees in the board game, the outdoor game, the role play and the game on computer, supports to spread educational, political or marketing messages.

It is also from this date, and thanks to technological advances in computer science, that the concept of Serious Game extends to video games.

Among the first Serious Games developed, one can quote OperationFrog (1983), three years later, the concept arrives in France with in particular the game "Le Sida"(1986). Other "retro serious games" are listed on the site Serious Game Classification from the research work of Alvarez and Djaouti.

But the theoretical reflection preceded the appearance of the first products, because the first true Serious Game was developed on July 4, 2002 in the United States, by and for the American army. "America's Army". This game is a new turning point in the field of computer-based learning. It is a very realistic military simulation video game worthy of commercial games. Its free and large-scale dissemination was intended not only to reveal the reality of military operations, but also to enhance the image of the army.

After the great success of "American Army" The sector of Serious Games has evolved greatly.

\subsection{The categories of Serious Game:}

The After the great success of "American Army" The sector of Serious Games has evolved greatly. This diversity has led to a diversification into Serious Games families.

According to research carried out by researchers in this field, there are several classification methods.

\subsubsection{A Classification of Serious Games according to the purpose:}

In 2006, researchers Julian Alvarez and Olivier Rampnoux proposed to classify serious games into five main categories: 


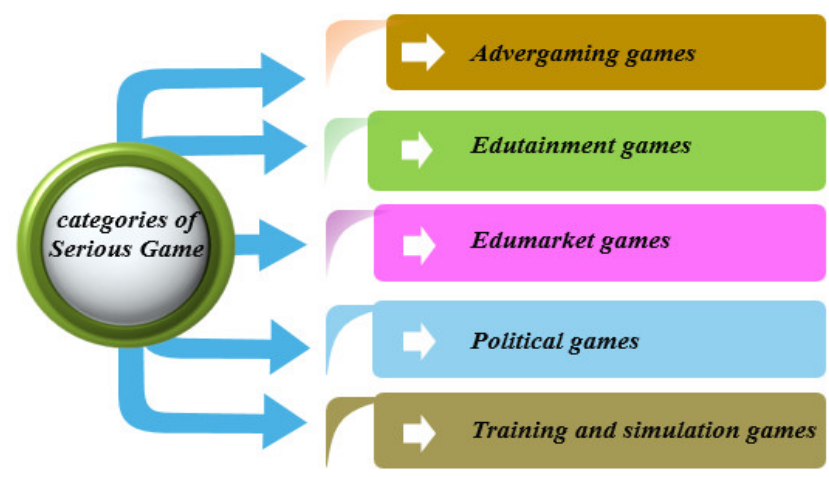

\subsubsection{A Classification of Serious Games by Gameplay:}

In 2007, the two researchers Ben Sawyer and Peter Smith proposed a different classification system, introducing the criterion of utility intent of the Serious Game with that of the associated market segment.

Since 2008, their classification system has been enriched with a third parameter: The Gameplay. Introduced by Damien Djaouti, Julian Alvarez and Olivier Rampnoux, he gives birth to a model called G / P / S (Gameplay, Allows, Sector):

Gameplay: This criterion notably indicates whether the Serious Game presents the possibility of winning or not. If it is not possible to win, the Gameplay is based on a video toy. This is called a Serious Play. If it is possible to win, then we are in the presence of a Serious Game based on a video game. This criterion also makes it possible to identify all the rules of the game put in the presence.

Allows: This is to list the "serious" functions associated with the videoludic base. Three major functions have been identified to date:

- Spread a message: The Serious Game aims to broadcast one or more messages. These can be of four different types: educational (ex: Edugames), informative (ex: Newsgames), persuasive (ex:Advergames) and subjective (ex: Militant games, Art games). A single game can accumulate several types of message.

- Practice: The Serious Game aims to improve the cognitive or physical abilities of the player (ex: exergames)

- Encourage the exchange of data: The Serious Game is designed to promote the exchange of data between players, or between the broadcaster of the game and the players (ex datagames).

Sector: this criterion gives two types of information:

- The scope of application of the Serious Game. For example: health, education, business, religion ...

- On the target audience of the Serious Game. For example: general public, professionals, students ... The ages of age are also to be specified.

So, we can classify the Serious Games either by the theme: (advertising, defense, politics, health, religion, ecologies) or by type, using the G / P / S model (advergame, persuasive game, newsgame, datagame).

\subsection{The characteristics of Serious Games:}

Usually, games share five specific characteristics. 
They are goal oriented. Learners must follow specific rules while playing them. They have some sort of feedback system, and there is often an element of competition. Finally, they are voluntary, meaning that learners decide whether they like to play or not.

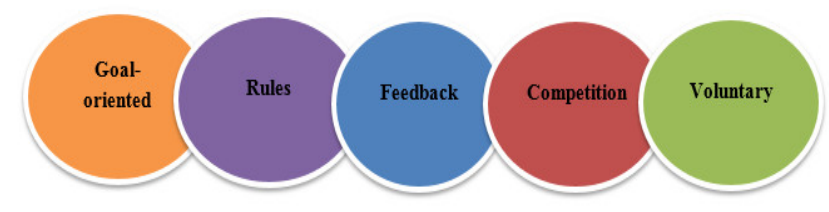

The Serious Game can have all the elements that characterize any other game. It can be goal-oriented with specific rules or a feedback system and a competitive comparative element. The only characteristic that is sometimes not present in the Serious Games is the voluntary character. Since these games are usually used in an educational setting or a training situation, players will often be invited to play some simulation or game.

\section{Why integrate the serious games into the school environment?}

As we have already pointed out, the introduction of play in the educational environment is not a recent idea. This process is taken up by teachers in nursery schools and primary to teach all subjects. This pedagogical approach aims to use the attractiveness and commitment inherent in the game to catalyze the learner's attention and engage him in his own learning (Dondlinger, 2007). Through play, the learner becomes the central actor of his formation, contrary to the passive position he occupies most of the time in traditional teaching.

He finds himself involved emotionally in the game, which facilitates the impregnation of his actions and decisions in his memory. The play can thus be advantageously used for facilitating the learning of certain skills for which traditional teaching methods are unsatisfactory (Federation of American Scientist, 2006; Mayo, 2007).

Despite the many advantages of learning by playing, this approach is today very little used in teaching. But with the arrival of new generations of learners accustomed to video games, this trend is about to change, the nature of the implicit didactic contract that prohibits learners from having fun in class as described by Chevallard (1999) is no longer appropriate for new learners.

Numerous research has shown that Games can be more effective than traditional methods in the acquisition of complex skills in higher education and in the workplace.

The integration of this type of game with the school environment allows the learner to train to perform a given task or maneuver and to study a real phenomenon reproduced in a virtual environment, learning more interactive and motivating.

Some studies also indicate that this type of game can sometimes lead to gains in confidence and concentration.

It is therefore clear that the Serious Games bring a great added value to the learning process. 


\section{Designing an educational software}

Designing and developing an educational software and a serious game requires a pedagogical motivation. For us, it resided in the recognition of recurrent difficulties of the students in the learning of mathematics, especially in mental calculation.

There are some software and gamesadaptable to different types of these difficulties for primary students, but we decide to developa different educational software that contains interactive exercises and a serious game.

In this part, we talk about what types of games would be compatible with mental math activity. Then, we compare our software with the other.

\subsection{Problem: mental calculation}

Several students have difficulty in calculating the four arithmetical operations, and especially in mental calculation. And it is known that the calculation is a central activity in in mathematics and not negligible in most scientific subjects. Thus, arithmetic operations are taught through different levels of primary, colleague and secondary school.

This learning proves to be difficult, especially for novices. Students are confronted with a set of epistemological obstacles.

Several approaches are proposed in the literature to help in the resolution of these difficulties. The first is to design exercises that meet certain criteria of relevance such as being related to real world problems, being interesting, allowing creativity and innovation. A second approach uses competition to stimulate participants' skills. A third approach is to design attractive and playful environments. Finally, the latest approach uses video games to motivate students.

So, our approach, we chose to develop an educational software that contains interactive exercises to master the calculation of four arithmetic operations and a serious game in mental calculation.

\subsection{Our educational software:}

To help students solve the difficulties in mental calculation and to motivate them, we design an educational software containing interactive exercises in algebra, and a serious game in mental calculation. It targets novices'students in the 6th year of primary school.

There are several types of video games that seemed to be representative of the gaming sphere: combat games, action-adventure games, action-RPG games, shooting games, sports games, games Racing games, electronic matching games, arcade video games, multiplayer Online Battle Arena games, strategy games, role playing games, platform games, puzzle games, adventure. After the analysis of each type of video games, we chose the action-RPG video game.

The principle of this game is that the player usually embodies a single character and the game happens in real time. The player evolves freely in a world and has certain goals to accomplish to advance in the adventure. In addition, most A-RPGs offer a system of advanced character evolution (equipment, characteristics, level of experience, etc.). All movements are on the same plane and the enemies are directly visible. Fighting begins when the enemy is within reach and takes place in the same environment. 
They usually interpret a character moving in a 3D universe to carry out different types of actions: discovering secret zones, collecting objectsetc., or fighting enemies, knocking out invaders, the scenarios can be various and varied.

As opposed to other existing software or games, our software is developed in Arabic, and can be used to acquire new concepts, in the consolidation phase or in the evaluation phase. So according to the pedagogical choice of the teachers. And from the interactive exercises, the studentwill learnthe methods for calculating addition, subtraction,

multiplication and division of integers and decimals numbers, and fractions. And He will develop their ability to mental calculating using our serious game.

Therefore, the interactives activities and the serious game allow the students in difficulty to be more motivated and therefore to become more involved in the activity.

We can summarize the goals to be achieved to this software in two:

The utilitarian aims are: To help the student in his school life, knowledge of the numbers and the processes, mental gymnastics.

The educational goals are: Developing auditory memory, attention, self-control, deploying a synthetic activity, keep the whole problem in mind when dealing with a part of it.

\subsection{Software screenshot:}

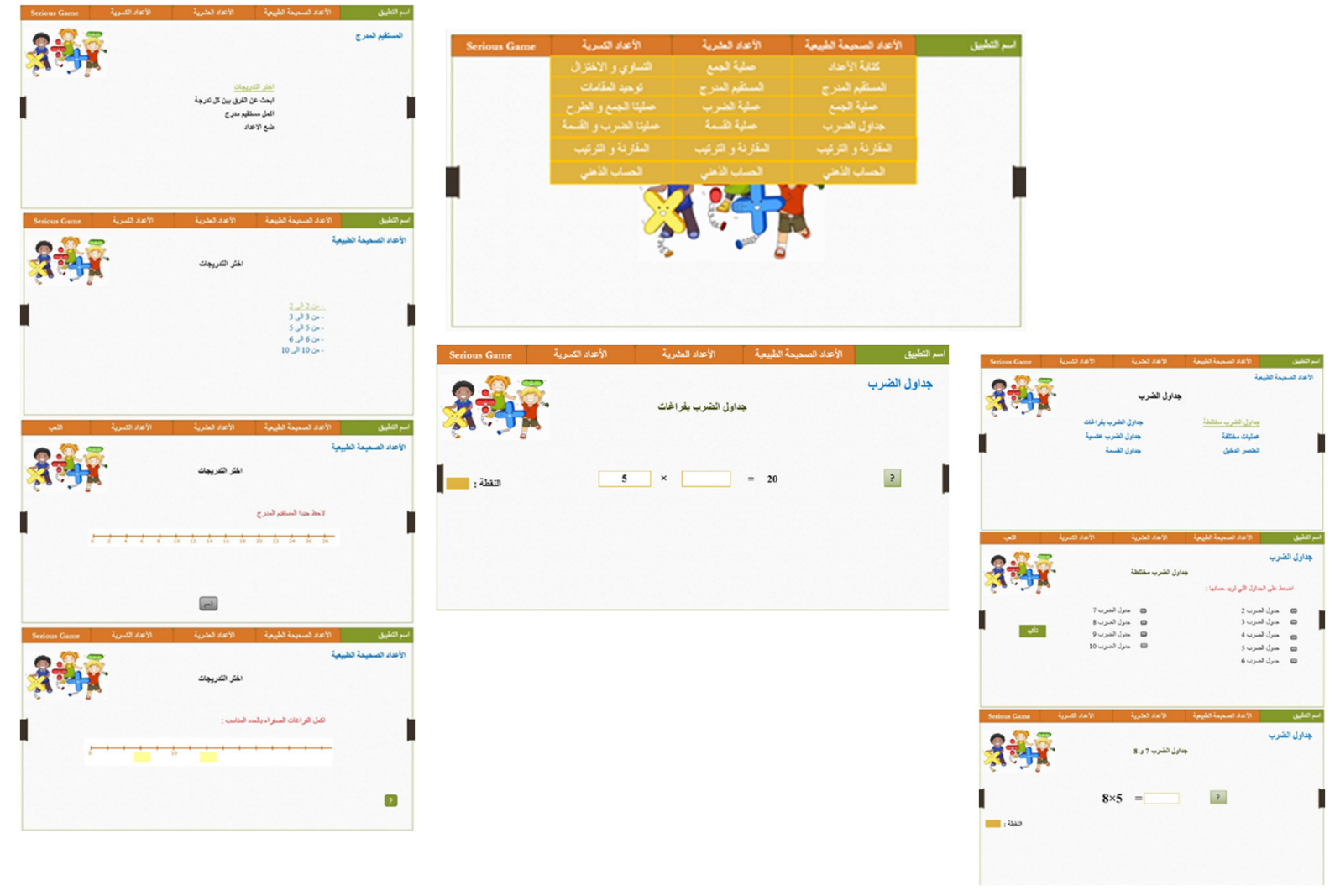




\section{Conclusion}

The concept of serious games intended to support learning through the practice of the game has been a great success in various fields, for which the pedagogies based on the use of serious game have expanded widely. They are in fact capable of soliciting the motivation of the learners and of enabling them to develop knowledge in the context of complex learning situations. For this we decided to develop educational software contains interactive exercises and serious game, in order to use the numerical practices of learners to develop their skills in mental calculation.

Several researches have been launched in the experimentation of these new learning tools. For this we will integrate our educational software into an educational scenario, and we will do an experimentation in primary school, and we will determine the impact of this educational software on the learning development of learners.

\section{REFERENCES}

[1] [1]ALVAREZ, Julian, " Du Jeu vidéo au Serious Game : approches culturelle, pragmatique et formelle ", Thèse de doctorat en science de l'information et de la communication, Université de Toulouse II le 17.12.2007.

[2] Damien DJAOUTI, «Serious Game Design Considérations théoriques et techniques sur la création de jeux vidéo à vocation utilitaire» Thèse de doctorat en Informatique, Université Toulouse III Paul Sabatier le 8.11.2011.

[3] ALVAREZ Julien, DJAOUTI Damien, Introduction au seriousgame, Ed. Questions théoriques, 2010.

[4] SANCHEZ, Eric., et al., "Jeux sérieux et pédagogie universitaire : de la conception à l'évaluation des apprentissages". Revue internationale des technologies en pédagogie universitaire,(2011). (en ligne : http://www.ritpu.org/IMG/pdf/RITPU_v08_n01-02_48.pdf).

[5] Zyda, M., « From Visual Simulation to Virtual Reality to Games»,IEEE Computer, vol. 38, n 9, 2005, p. 2532.

[6] Viau, R., La motivation en contexte scolaire, Bruxelles : De Boeck,1997.

[7] Serious Game classification, site créé en 2006 par LudoScience (Julian Alvarez, Damien Djaouti en association avec les chercheurs des laboratoires IRIT et LARA des universités de Toulouse II et III). Disponible sur : serious.gameclassification.com.

[8] Sébastien George et Éric Sanchez, Actes de l'Atelier " Jeux Sérieux : conception et usages 》. 4ème Conférence francophone sur les Environnements Informatiques pour l'Apprentissage Humain. 23 juin 2009.

[9] Cobb, P., Confrey, J., diSessa, A., Lehrer, R., Schauble, L. (2003). Design experiments in educational research. Educational Researcher, 32, 1: 9-13.

[10] Malone, T. W., Lepper, M. R., " Making learning fun: Ataxonomy of intrinsic motiavations for learning ", Aptitude, learning andinstruction: III. Conative and affective process analyses, 1987, p. 223-253. 
Loubna El Azizi, Aziz Arbai. Serious Games for the Development of Learning. Transactions on Machine Learning and Artificial Intelligence, Vol 5 No 4 August (2017); p: 448-456

[11] Jeux sérieux / Seriousgames, site édité par le CERIMES (Centre de Ressources et d'Information sur les Multimédias pour l’Enseignement Supérieur). Disponible sur : http://www.jeux-serieux.fr/

[12] "Game Based Learning, Apprendre avec les jeux vidéo » Institut suisse des médias pour la formation et la culture, décembre

2013 http://guides.educa.ch/sites/default/files/educa.guides_gamebasedlearning_fr_0.pdf.

[13] L'historique des rapports entre pédagogie et jeu : http://histgeo.discip.ac-caen.fr/ludus/histjeduc.htm. 